\title{
Household exposure to pesticides and risk of childhood acute leukaemia
}

\author{
F Menegaux, A Baruchel, Y Bertrand, B Lescoeur, G Leverger, B Nelken, D Sommelet, D Hémon, \\ J Clavel
}

See end of article for authors' affiliations ..................... Correspondence to: Dr F Menegaux, INSERM U170, 16, av. Paul Vaillant-Couturier, F-94807 Villejuif Cedex; menegaux@vjf.inserm.fr

Accepted 6 October 2005

\begin{abstract}
Objectives: To investigate the relation between childhood acute leukaemia and household exposure to pesticides.

Methods: The study included 280 incident cases of acute leukaemia and 288 controls frequency matched on gender, age, hospital, and ethnic origin. The data were obtained from standardised face to face interviews of the mothers with detailed questions on parental occupational history, home and garden insecticide use, and insecticidal treatment of pediculosis. Odds ratios were estimated using unconditional regression models including the stratification variables parental socioeconomic status and housing characteristics.

Results: Acute leukaemia was observed to be significantly associated with maternal home insecticide use during pregnancy $(\mathrm{OR}=1.8,95 \% \mathrm{Cl} 1.2$ to 2.8$)$ and during childhood $(\mathrm{OR}=1.7,95 \% \mathrm{Cl} 1.1$ to 2.4$)$, with garden insecticide use $(O R=2.4,95 \% \mathrm{Cl} 1.3$ to 4.3$)$, and fungicide use $(\mathrm{OR}=2.5,95 \% \mathrm{Cl} 1.0$ to 6.2) during childhood. Insecticidal shampoo treatment of pediculosis was also associated with childhood acute leukaemia $(\mathrm{OR}=1.9,95 \% \mathrm{Cl} 1.2$ to 3.3$)$.

Conclusion: The results reported herein support the hypothesis that various types of insecticide exposure may be a risk factor for childhood acute leukaemia. The observed association with insecticidal shampoo treatment of pediculosis, which has never been investigated before, requires further study.
\end{abstract}

$\mathrm{L}$ eukaemia is the most common cancer in childhood with an incidence rate of 43.1 per 1000000 per year in France ${ }^{1}$ -and, with the exception of ionising radiation and certain rare genetic syndromes, its aetiology remains largely unknown. Several studies ${ }^{2-8}$ and two reviews of epidemiological studies ${ }^{10}$ have suggested that household pesticide exposure may be associated with childhood leukaemia. The studies considered different definitions of exposure (home or garden pesticide use, pesticides overall, insecticides), different periods of exposure (pregnancy, childhood, or both), different subtypes of the cases included (acute lymphoblastic leukaemia: ALL or acute non-lyphoblastic leukaemia: ANLL) and different age groups ( $<9$ years, $<10$ years, $<15$ years, $<18$ years). Residential pesticide exposure has also been associated with other childhood cancers (lymphoma, brain tumour, neuroblastoma, Wilm's tumour, and Ewing's sarcoma). Moreover, the International Agency for Research on Cancer (IARC) considers the "spraying and application of non-arsenical insecticides entailing exposures" to be, as a whole, probably carcinogenic to humans. ${ }^{11}$

The present study was designed to assess the role of environmental and genetic factors in the aetiology of childhood acute leukaemia. This paper analyses the relation between pesticide exposure and childhood acute leukaemia.

\section{METHODS}

\section{Cases and controls}

The detailed study design has been reported elsewhere. ${ }^{12}$ Briefly, the cases were children under the age of 15 years hospitalised following recent diagnosis ( $<2$ months) of primary leukaemia between 1995 and 1999 in the hospitals of Lille, Lyon, Nancy, and Paris (France). Special care was paid to selecting an appropriate hospitalised control group. The hospital based design of the study was chosen because case and control blood samples were required. Controls were children hospitalised in the same hospital as cases, mainly in orthopaedic and emergency departments, and mainly residing in the same area as cases (that is, the catchment area of the hospital). Many different diagnostic categories were included in order to avoid selection biases in the event that a particular disease was related to the exposures of interest. However, children hospitalised for cancer or a major congenital malformation were not eligible for the study, because those diseases may share risk factors with leukaemia.

Recruitment was frequency matched by age, gender, hospital, and ethnic origin (white, North African, other). Two case and two control mothers refused to participate. The physicians requested that the interviewers refrain from contacting the mothers of 13 cases (nine ALL and four ANLL) whose condition was critical. All the control mothers were contacted. One control child who had been adopted was excluded. Thus, a total of 280 incident cases of acute leukaemia confirmed by cytology and 288 controls were included in the study.

\section{Data collection}

The mothers of the cases and controls were interviewed face to face by specifically trained medical doctors using a standard questionnaire. The questions addressed the parents' sociodemographic characteristics, the child's pre- and postnatal characteristics and medical history, the familial history of cancer and autoimmune diseases, and the parents' occupations and habits.

The questions relating to pesticide exposure covered pregnancy and the period from birth to diagnosis, and included home insecticide and garden pesticide (insecticides,

Abbreviations: ALL, acute lymphoblastic leukaemia; ANLL, acute nonlymphoblastic leukaemia; IARC, International Agency for Research on Cancer 
herbicides, and fungicides) use by the mother. The questions on pesticide use at home and in the garden were closed questions: "Did you regularly use insecticides at home?", "Did you use, yourself, gardening chemicals: fertilizer, herbicides, insecticides, fungicides, others?". The questionnaire also addressed the parents' occupations during pregnancy and during childhood of study subjects.

The index child's direct pesticide exposure to pediculosis treatments during childhood was also determined through an open question on the types of treatment received.

\section{Statistical analysis}

All the analyses were performed using the SAS software packages (version 9.1, Cary, NC, USA). Odds ratios (OR) were estimated using unconditional logistic regression models including the stratification variables: gender, age, hospital,

Table 1 Sample description for the cases and controls

\begin{tabular}{|c|c|c|c|}
\hline & $\begin{array}{l}\text { Cases (\%) } \\
(n=280)\end{array}$ & $\begin{array}{l}\text { Controls (\%) } \\
(\mathrm{n}=288)\end{array}$ & p Value \\
\hline \multicolumn{4}{|l|}{ Diagnostic categories } \\
\hline Acute lymphoblastic leukaemia & $240(86)$ & - & \\
\hline Acute non-lymphoblastic leukaemia & 40 (14) & - & \\
\hline $\begin{array}{l}\text { Injury (fractures, wounds, burns, } \\
\text { etc) }\end{array}$ & - & $154(54)$ & \\
\hline $\begin{array}{l}\text { Osteoarticular diseases } \\
\text { (osteomyelitis, arthritis, etc) }\end{array}$ & - & $100(35)$ & \\
\hline Gastrointestinal, genitourinary & - & $17(6)$ & \\
\hline Minor congenital disorders & - & $6(2)$ & \\
\hline Other & - & $11(4)$ & \\
\hline Gender & & & \multirow[t]{2}{*}{ NS } \\
\hline Male & $166(59)$ & $168(58)$ & \\
\hline Age (years) & & & * \\
\hline$<2$ & $33(12)$ & $51(18)$ & \\
\hline $2-3$ & $85(30)$ & $53(18)$ & \\
\hline $4-6$ & $83(30)$ & 79 (27) & \\
\hline $7-10$ & $41(15)$ & $63(22)$ & \\
\hline$\geqslant 11$ & 38 (14) & $42(15)$ & \\
\hline Hospital & & & NS \\
\hline Lille & $39(14)$ & $26(9)$ & \\
\hline Lyon & $36(13)$ & $35(12)$ & \\
\hline Nancy & $23(8)$ & $22(8)$ & \\
\hline Paris & $182(65)$ & $205(71)$ & \\
\hline Ethnic origin & & & NS \\
\hline White & $244(87)$ & $236(82)$ & \\
\hline North African & $15(5)$ & $25(9)$ & \\
\hline Caribbean & $4(1)$ & $5(2)$ & \\
\hline African & $2(1)$ & $6(2)$ & \\
\hline Asian, Middle Eastern & $2(1)$ & $6(2)$ & \\
\hline Mixed, other & $13(5)$ & $10(3)$ & \\
\hline Maternal education & & & NS \\
\hline$\leqslant$ High school & $190(68)$ & $176(62)$ & \\
\hline$>$ High school & $90(32)$ & $108(38)$ & \\
\hline Paternal education & & & NS \\
\hline$\leqslant$ High school & $181(68)$ & $171(63)$ & \\
\hline$>$ High school & $87(32)$ & 99 (37) & \\
\hline Working mother at time of interview & & & NS \\
\hline Yes $v$ no & $173(62)$ & $191(67)$ & \\
\hline Socioprofessional categories† & & & NS \\
\hline $\begin{array}{l}\text { Professional, technical workers, } \\
\text { administrators, and managers }\end{array}$ & $147(52)$ & $160(56)$ & \\
\hline Clerical, sales, and services workers & $55(20)$ & 49 (17) & \\
\hline Factory and agricultural workers & $78(28)$ & $76(27)$ & \\
\hline $\begin{array}{l}\text { Place of residence (number of } \\
\text { inhabitants) }\end{array}$ & & & NS \\
\hline$<5000$ & $40(14)$ & 37 (12) & \\
\hline 5000-9999 & $10(4)$ & $5(2)$ & \\
\hline 10000-19999 & $5(2)$ & $4(1)$ & \\
\hline $20000-49999$ & $13(5)$ & $5(2)$ & \\
\hline 50000-99999 & $8(3)$ & $2(1)$ & \\
\hline 100000-199999 & $13(5)$ & $3(1)$ & \\
\hline 200000-199999 & $41(15)$ & $46(16)$ & \\
\hline$\geqslant 2000000$ & $148(53)$ & $186(65)$ & \\
\hline $\begin{array}{l}\text { NS, } p>0.05 \text {. } \\
{ }^{*} p<0.01 \text {. } \\
\text { †Socioprofessional categories: best occ } \\
\text { mother or father. }\end{array}$ & ppational o & ctivity of ch & $\mathrm{Id}^{\prime} \mathrm{s}$ \\
\hline
\end{tabular}

and ethnic origin. Potential confounding by sociodemographic characteristics (maternal educational level and parental socioprofessional category), place of residence (rural: $\leqslant 5000$ inhabitants and urban: >5000 inhabitants), and type of housing (apartment or house) was considered in the various analyses. Adjustments were also performed on other variables previously identified as related to acute leukaemia in this study (familial history of cancer or autoimmune disease, early common infections, daycare attendance, prolonged breast feeding, and residence in the vicinity of a gas station or garage). ${ }^{12-16}$

Only seven cases and four controls came from outside the catchment area of the hospital ( $3 \% v 1 \%, \mathrm{p}=0.37)$. When we restricted the analyses to cases and controls residing inside the catchment area of the hospital, the results were unchanged. Thus, we decided to present results on the entire study population.

\section{RESULTS}

\section{Study population}

Out of the 280 cases included in the study, acute lymphoblastic leukaemia (ALL) was diagnosed in 240 and acute nonlymphoblastic leukaemia (ANLL) in 40 cases.

Most of the controls (89\%) were recruited in an orthopaedic or emergency department (table 1). Sixty per cent of the cases were 2-6 years old, versus 55\% of the controls. Good case control comparability of maternal and paternal schooling was obtained after adjustment for stratification variables (table 1). The case and control groups contained the same proportion of working mothers and had similar socioprofessional category distributions.

\section{Parental occupational exposure to pesticides}

Five cases and three controls had a parent (mother or father) who was occupationally exposed to pesticide during the childhood of the index child. Only two cases and one control had a mother who was occupationally exposed to pesticide during the pregnancy of the index child.

\section{Home insecticide use}

We observed a significant association between childhood acute leukaemia and home insecticide use $(\mathrm{OR}=1.8,95 \% \mathrm{CI}$ 1.2 to 2.8 ) during pregnancy and $\mathrm{OR}=1.7$ (95\% CI 1.1 to 2.4 ) during childhood) (table 2). When the exposure periods were considered individually, home insecticide use was only significantly associated with childhood acute leukaemia when exposure occurred during both pregnancy and childhood (OR $=1.6$ (95\% CI 0.8 to 3.3 ) during pregnancy only, $\mathrm{OR}=1.4(95 \%$ CI 0.8 to 2.3$))$ during childhood only, and $\mathrm{OR}=2.0$ (95\% CI 1.2 to 3.1 ) during pregnancy and childhood).

\section{Garden pesticide use}

Overall, pesticide use for gardening during childhood $(\mathrm{OR}=1.7,95 \% \quad 1.1$ to 2.7$)$ was associated with acute leukaemia. Garden insecticide use during childhood and garden fungicide use during childhood were associated with childhood acute leukaemia ( $\mathrm{OR}=2.4 \quad(95 \% \quad 1.3$ to 4.3$)$, $\mathrm{OR}=2.5$ ( 1.0 to 6.2 ), respectively), while garden herbicide use was not ( $\mathrm{OR}=1.4,95 \% \mathrm{CI} 0.8$ to 2.4 ). When the periods of exposure were considered individually, garden pesticide use was associated with childhood acute leukaemia when exposure occurred during both pregnancy and childhood ( $\mathrm{OR}=1.2$ (95\% CI 0.5 to 3.0) during pregnancy only, OR $=1.5$ (95\% 0.9 to 2.5 ) during childhood only, and OR $=5.6$ (95\% CI 1.6 to 20 ) during pregnancy and childhood. Garden insecticide use remained associated with acute leukaemia only when the period of exposure was during childhood ( OR $=0.6(95 \%$ CI 0.1 to 7.6 ) during pregnancy only, $\mathrm{OR}=1.4(95 \% \mathrm{CI} 1.3$ to 4.7 ) 


\begin{tabular}{|c|c|c|c|c|c|c|c|c|}
\hline & \multicolumn{4}{|c|}{ Pesticide use during pregnancy* } & \multicolumn{4}{|c|}{ Pesticide use during childhood $\dagger$} \\
\hline & $\begin{array}{l}\text { Cases } \\
(\mathrm{n}=280)\end{array}$ & $\begin{array}{l}\text { Controls } \\
\text { ( } \mathrm{n}=288)\end{array}$ & OR‡ & $95 \% \mathrm{Cl}$ & $\begin{array}{l}\text { Cases } \\
(n=280)\end{array}$ & $\begin{array}{l}\text { Controls } \\
(\mathrm{n}=288)\end{array}$ & OR‡ & $95 \% \mathrm{Cl}$ \\
\hline \multicolumn{9}{|c|}{ Home insecticide use } \\
\hline Never & 188 & 223 & 1.0 & Reference & 164 & 198 & 1.0 & Reference \\
\hline Ever & 92 & 60 & 1.8 & $(1.2-2.8)$ & 111 & 84 & 1.7 & $(1.1-2.4)$ \\
\hline Missing & 0 & 5 & & & 5 & 6 & & \\
\hline \multicolumn{9}{|c|}{ Garden pesticide use } \\
\hline Never & 252 & 272 & 1.0 & Reference & 191 & 198 & 1.0 & Reference \\
\hline Ever & 14 & 7 & 2.5 & $(0.8-7.2)$ & 70 & 45 & 1.7 & $(1.1-2.7)$ \\
\hline Missing & 0 & 6 & & & 2 & 6 & & \\
\hline Insecticide & 9 & 4 & 1.9 & $(0.6-6.5)$ & 47 & 20 & 2.4 & (1.3-4.3) \\
\hline Herbicide & 6 & 3 & 5.9 & $(0.7-52)$ & 40 & 31 & 1.4 & $(0.8-2.4)$ \\
\hline Fungicide & 3 & 0 & - & & 17 & 8 & 2.5 & $(1.0-6.2)$ \\
\hline
\end{tabular}

during childhood only, and OR $=3.4$ (95\% CI 0.7 to 17 ) during pregnancy and childhood).

\section{Insecticide treatments for pediculosis}

Pediculosis during childhood was more frequently reported for cases than for controls with ORs of 1.5 (95\% CI 0.9 to 2.5 ) for one episode and 1.9 (95\% CI 1.1 to 3.3 ) for two or more episodes (table 3). Overall, the use of shampoos to treat pediculosis was associated with childhood leukaemia $(\mathrm{OR}=1.9,95 \%$ CI 1.1 to 3.2$)$. Various insecticidal shampoos were reported and were pyrethroid based (65 cases and 55 controls, $\mathrm{OR}=2.0$ (95\% CI 1.1 to 3.4$)$ ), organochlorine based ( six cases and four controls, OR $=2.1$ ( $95 \%$ CI 0.5 to 8.7)), and organophosphorus based (five cases and 10 controls, $\mathrm{OR}=0.7$ (95\% CI 0.2 to 2.4$)$ ). The estimates were similar for ALL and ANLL.

\section{Adjustments}

The estimates were unchanged when the use of insecticides at home, for gardening, and to treat pediculosis were considered together in the same model. There was no change in the results after adjustment for parental socioprofessional categories, parental educational levels, place of residence (urban or rural), or type of housing (apartment or house). Moreover, adjusting separately or simultaneously for familial history of cancer or

Table 3 Pediculosis during childhood and risk of childhood acute leukaemia

\begin{tabular}{|c|c|c|c|c|}
\hline & $\begin{array}{l}\text { Cases } \\
(n=280)\end{array}$ & $\begin{array}{l}\text { Controls } \\
(n=288)\end{array}$ & $\mathrm{OR}^{*}$ & $95 \% \mathrm{Cl}$ \\
\hline \multicolumn{5}{|l|}{ Pediculosis } \\
\hline Never & 180 & 195 & 1.0 & Reference \\
\hline Ever & 98 & 90 & 1.6 & $(1.0-2.6)$ \\
\hline Missing & 2 & 3 & & \\
\hline Once & 51 & 48 & 1.5 & $(0.9-2.5)$ \\
\hline Twice or more & 47 & 42 & 1.9 & $(1.1-3.3)$ \\
\hline \multicolumn{5}{|l|}{ Pediculosis treatments } \\
\hline No treatment† & 179 & 194 & 1.0 & Reference \\
\hline Insecticidal shampoo & 70 & 60 & 1.9 & $(1.1-3.2)$ \\
\hline Other (vinegar, sweet almond & 1 & 3 & 0.3 & $(0.03-2.9)$ \\
\hline \multicolumn{5}{|l|}{ oil) } \\
\hline Missing & 30 & 31 & & \\
\hline Pyrethroid & 65 & 55 & 2.0 & $(1.1-3.4)$ \\
\hline Pyrethroid only & 59 & 46 & 2.2 & $(1.2-3.8)$ \\
\hline Lindane (organochlorine) & 6 & 4 & 2.1 & $(0.5-8.7)$ \\
\hline Malathion (organophosphorus) & 5 & 10 & 0.7 & $(0.2-2.4)$ \\
\hline
\end{tabular}

autoimmune disease, frequent early common infections, daycare attendance, prolonged breastfeeding, and residence in the vicinity of a gas station or garage-factors which were previously related to childhood acute leukaemia in the present study - did not modify the results.

The results remained stable over the age groups and were similar for ALL and ANLL.

\section{Missing values}

The data on the shampoos used to treat pediculosis were missing from about $10 \%$ of the questionnaires. A sensitivity analysis was carried out to evaluate the potential impact of those missing data on the estimates. When the missing data were all considered exposures and then all considered nonexposures, the odds ratios remained greater than 1 , and were close to significance or significant: OR $=1.5$ (95\% CI 0.9 to 2.5 ) and $\mathrm{OR}=2.0$ (95\% CI 1.2 to 3.3 ), respectively. In the extreme and unlikely scenario that the missing data were non-exposures for cases and exposures for controls, the odds ratio would be 1.2 (95\% CI 0.7 to 1.9$)$.

\section{DISCUSSION}

The present study evidenced associations between childhood acute leukaemia and three sources of exposure to insecticides: home insecticide use, garden insecticide use, and insecticide use for pediculosis. The number of parents who were occupationally exposed to pesticides was too small to allow further analyses.

The size of the present study enabled detection of minimum odds ratios of 1.6, 1.9, and 2.2 for control exposure prevalences of $20 \%, 10 \%$, and $5 \%$, respectively. These prevalences are of the same order of magnitude as those for home insecticide use during pregnancy and during childhood $(21 \%$ and $29 \%$, respectively), garden insecticide use during pregnancy and during childhood ( $1 \%$ and $5 \%$, respectively), and insecticidal pediculosis treatment during childhood $(25 \%)$.

The oncology departments recruit patients from more distant places than do control departments, and this could have introduced bias. In order to keep cases and controls comparable in terms of socioeconomic category and rural/ urban status, most of the children (all but seven cases and four controls) were living in the same administrative region as the hospital location.

The case and control mothers were very similar with respect to education, occupation, socioeconomic status, and place of residence. The results were unchanged after additional adjustment for the parents' socioprofessional categories, educational levels, place of residence (urban or rural), or type of housing 
(apartment or house). The use of standardised questionnaires and similar interviewing conditions for case and control mothers reduced potential differential misclassifications.

Pesticide exposure is a growing public concern which might induce recall bias. However, our study took place in the period 1995-99 when the subject was far less in the media in France than it is now. Nevertheless, a recall bias cannot strictly be ruled out. The information on shampoos to treat pediculosis may be unreliable, but probably in the same way for the cases and controls.

A variety of possible confounding factors were incorporated in the model in order to test the consistency of the association between insecticide exposure and acute leukaemia. The factors included variables that had previously been shown to be related to childhood acute leukaemia in the present study. The variables related to home or garden insecticide use and pediculosis treatment were also incorporated simultaneously. Adjusted for separately or taken together, none of those variables had any influence on the results. With respect to shampoos for pediculosis, sensitivity analyses showed that loss of association would only occur for unlikely distributions of missing data and that the OR would still be 1.2 in the extreme scenario, in which all the missing case data consisted of non-exposures and all the missing control data consisted of exposures.

The shampoos used to treat pediculosis could have contained three types of insecticide, possibly in combination: pyrethroid, organochlorinated (lindane), and organophosphorus (malathion) insecticides. To the authors' knowledge, no previous study has investigated direct childhood pesticide exposure due to insecticidal shampoos. The results reported herein therefore need to be replicated and investigated further.

The results for residential pesticide exposure are consistent with previously published studies. Home pesticide use during pregnancy or childhood was associated with childhood acute leukaemia in the six studies which investigated that exposure. ${ }^{2-6} 8$ Leiss and Savitz (1995) reported an association with pesticide strip use during pregnancy and childhood. ${ }^{4}$ The authors cited dichlorvos, a specific insecticide used in pesticidal strips, which is carcinogenic in animals and classed as possibly carcinogenic for humans by the IARC. In addition, "spraying and application of non-arsenical insecticides entailing exposures" have been classified as probably carcinogenic by the IARC. ${ }^{11}$

The association with garden pesticide use is less consistent: two studies found an association between childhood leukaemia and garden pesticide use during pregnancy, ${ }^{35}$ one study found an association with garden pesticide use during childhood, ${ }^{3}$ and three studies did not find any association irrespective of the period of exposure. ${ }^{468}$ The incidence of childhood cancer was not related to local agricultural pesticide use in an ecological study. ${ }^{17}$ However, the same authors subsequently conducted a case control study and reported associations between childhood leukaemia and local agricultural use of two common types of pesticide, metham sodium $(\mathrm{OR}=2.05(95 \% \mathrm{CI} 1.01$ to 4.17$))$, and difocol $(\mathrm{OR}=1.83(95 \%$ CI 1.0 to 3.22$)) .{ }^{18}$

In conclusion, the findings of the present study reinforce the hypothesis already suggested by the literature that household pesticide exposure may play a role in the aetiology of childhood acute leukaemia. At this stage, no specific product can be singled out and a causal relation remains questionable. However, the consistency of our results and the results from previous studies suggests that it may be opportune to consider preventive action.

\section{ACKNOWLEDGEMENTS}

This work was supported by grants from INSERM, the French Ministère de l'Environnement, the Association pour la Recherche contre le Cancer, the Fondation de France, the Fondation Jeanne Liot, the Fondation Weisbrem-Berenson, the Ligue Contre le Cancer du Val de Marne, and the Ligue Nationale Contre le Cancer.

We are grateful to Drs Diane Farkas, Kamila Kebaïli, Anne Lambilliotte, Dominique Steschenko, Martine Zagouri, and Naïma Belkacem, who conducted the interviews, and to Martine Valdes, Isabelle Jaussent, Laurence Mandereau, and Dominique Ridondelli for technical assistance. We also thank the heads of the departments who helped us to include their patients as controls: Professors Bensahel, Bérard, Carlioz, Deberigny, Felipe, Herbault, Lascombes, Pouliquen, and Rigault. We are grateful to Andrew Mullarky for his skilful revision of the manuscript.

\section{Authors' affiliations}

F Menegaux, D Hémon, J Clavel, INSERM, U170, IFR69, Villejuif,

France

A Baruchel, Department of Pediatric Hematology, Saint-Louis Hospital, Paris, France

Y Bertrand, Department of Pediatric Hematology, Debrousse Hospital, Lyon, France

B Lescoeur, Department of Pediatric Hematology-Immunology, Robert Debré Hospital, Paris, France

G Leverger, Department of Pediatric Hematology, Armand Trousseau Hospital, Paris, France

B Nelken, Department of Pediatric Hematology-Oncology, Jeanne de Flandre Hospital, Lille, France

D Sommelet, Department of Pediatric Hematology, Brabois Hospital, Nancy, France

Competing interests: none.

Ethics approval: the present study has been approved by the National Commission for Data protection and the Liberties (no 339392) and by the ethic committee (no 94.0356).

\section{REFERENCES}

1 Clavel J, Goubin A, Auclerc MF, et al. Incidence of childhood leukaemia and non-Hodgkin's lymphoma in France: National Registry of Childhood Leukaemia and Lymphoma, 1990-1999. Eur J Cancer Prev 2004;13:97-103.

2 Buckley JD, Robison LL, Swotinsky R, et al. Occupational exposures of parents of children with acute nonlymphocytic leukaemia: a report from the Childrens Cancer Study Group. Cancer Res 1989:49:4030-7.

3 Infante-Rivard C, Labuda D, Krajinovic M, et al. Risk of childhood leukaemia associated with exposure to pesticides and with gene polymorphisms. Epidemiology 1999;10:481-7

4 Leiss JK, Savitz DA. Home pesticide use and childhood cancer: a case-control study. Am J Public Health 1995;85:249-52.

5 Lowengart RA, Peters JM, Cicioni C, et al. Childhood leukaemia and parents' occupational and home exposures. J Natl Cancer Inst 1987;79:39-46.

6 Ma X, Buffler PA, Gunier RB, et al. Critical windows of exposure to household pesticides and risk of childhood leukaemia. Environ Health Perspect 2002;110:955-60.

7 Meinert R, Kaatsch P, Kaletsch U, et al. Childhood leukaemia and exposure to pesticides: results of a case-control study in northern Germany. Eur J Cancer 1996;32A: 1943-8.

8 Meinert R, Schuz J, Kaletsch U, et al. Leukaemia and non-Hodgkin's lymphoma in childhood and exposure to pesticides: results of a register-based case-control study in Germany. Am J Epidemiol 2000;151:639-46, discussion 47-50

9 Daniels JL, Olshan AF, Savitz DA. Pesticides and childhood cancers. Environ Health Perspect 1997; 105:1068-77.

10 Zahm SH, Ward MH. Pesticides and childhood cancer. Environ Health Perspect 1998;106(Suppl 3):893-908.

11 IARC. Monographs on the evaluation of carcinogenic risk to humans, vol 53 1991

12 Perrillat F, Clavel J, Auclerc MF, et al. Day-care, early common infections and childhood acute leukaemia: a multicentre French case-control study. Br J Cancer 2002;86:1064-9.

13 Perillat-Menegaux F, Clavel J, Auclerc MF, et al. Family history of autoimmune thyroid disease and childhood acute leukaemia. Cancer Epidemiol Biomarkers Prev 2003;12:60-3.

14 Perrillat F, Clavel J, Jaussent I, et al. Family cancer history and risk of childhood acute leukaemia (France). Cancer Causes Control $2001 ; 12: 935-41$

15 Perrillat F, Clavel J, Jaussent I, et al. Breast-feeding, fetal loss and childhood acute leukaemia. Eur J Pediatr 2002;161:235-7.

16 Steffen C, Auclerc MF, Auvrignon A, et al. Acute childhood leukaemia and environmental exposure to potential sources of benzene and other hydrocarbons; a case-control study. Occup Environ Med 2004;61:773-8.

17 Reynolds P, Von Behren J, Gunier RB, et al. Childhood cancer and agricultural pesticide use: an ecologic study in California. Environ Health Perspect 2002;110:319-24.

18 Reynolds P, Von Behren J, Gunier RB, et al. Agricultural pesticide use and childhood cancer in California. Epidemiology 2005;16:93-100. 